Fifth International Conference on Sustainable Construction Materials and

Technologies. http://www.claisse.info/Proceedings.htm

\title{
CEMENT STABILIZATION EFFECT ON MECHANICAL AND HYGRIC PROPERTIES OF COMPACTED EARTH
}

\author{
Noha Al Haffar ${ }^{1,2}$, Antonin Fabbri ${ }^{1}$, Fionn McGregor ${ }^{1}$, Horacio Colina ${ }^{2}$ \\ ${ }^{1}$ LTDS, UMR 5513 CNRS, ENTPE, 2 rue Maurice Audin, 69100 Vaulx-en-Velin, \\ France \\ ${ }^{2}$ Association Technique de l'Industrie des Liants Hydrauliques, 7 place de la Défense, \\ 92974 Paris-La-Défense Cedex, France \\ E-mail: noha.alhaffar@entpe.fr, antonin.fabbri@entpe.fr, fionn.mcgregor@entpe.fr \\ and h.colina@atilh.fr
}

\begin{abstract}
Experimental investigations were carried out in this work to evaluate the impact of stabilisation on the mechanical and hygric properties of a reference soil-cement couple. Unstabilized and stabilized soils with two amounts of cement were examined. Compacted earth samples were prepared at their optimum water content and dry density. The effectiveness of stabilisation were verified by simple compressive strength tests conducted on cylindrical samples at different ages of curing. In a second step, the water vapour resistance factor was determined following the so-called "wetcup" method at the age of 28 and 90 days. Then the moisture buffering value was measured according to the Nordtest protocol. On one hand, compressive strength had been shown a dependency on the cement amount and the curing age. On the other hand, it has been found that increasing cement amount increase the vapour resistance, but it has a limited impact on the measured MBV.
\end{abstract}

Keywords: Compacted earth, cement stabilization, curing age, compressive strength, vapor permeability, moisture buffering.

\section{INTRODUCTION}

In pursuit of the world awareness for sustainable development, those who design and govern the codes of buildings are now keenly interested in earthen architecture and construction. The renewed interest of earth lies in its sustainability since it is a local material that can be produced and used immediately on the construction site or nearby and does not require industrial processing. The environmental advantage of earth construction referred to their low embodied energy, make them extremely competitive when compared to conventional materials and construction techniques (Morel et al., 2001). A second feature of earthen materials is their well-established ability to store 
and manage heat which guarantee interior comfort in shelters (Heathcote, 2011; Allinson and Hall, 2012; Pacheco-Torgal and Jalali, 2012; Soudani et al., 2016).

In return, the hydrophilic nature of raw earth significantly increases the deformability of the material, reduces its strength and even change its type of behavior, especially in humid environment (Morel, Bui and Hamard, 2012). Despite such characteristics, the existence of ancient earth constructions can be held as a proof of their long-term durability (Morel et al., 2013). However, it must be recognized that much knowledge of traditional manufacturing techniques has been lost. Moreover, in function of the local geological environment, the material variability (composition, granular distribution, etc.) may be significant. In consequence, even though some earths can be directly used as a building material in their immediate environment, others may be inadequate. A way to increase the durability to water and to maximize the use of local material (and thus reduce the energy and economic costs due to transport) is to stabilize local earth by adding hydraulic binders, such as cement (Walker, 1995; Bui et al., 2009; Venkatarama Reddy, 2012).

Over the past few decades, scientists have devoted substantial effort to understand the impact of cement stabilization on the properties of compacted earth, with a particular attention to their mechanical characteristics (Walker, 1995; Morel, Pkla and Walker, 2007; Arrigoni et al., 2017) and their water durability (Bui et al., 2009; Cid-Falceto, Mazarrón and Cañas, 2012). The common feature shared by these studies is that increasing cement content increases the mechanical performances of stabilized compacted earths and results in a substantial improvement of their durability toward water erosion. On the other side, several researches show that cement stabilization reduces the vapour permeability of compacted earths and their moisture buffering capacities (McGregor et al., 2012, 2014). Nevertheless, the majority of existing findings concern the effect of stabilization with ordinary Portland cement (OPC) only. However, optimizing cement stabilization of compacted earths, which remains one of the less treated topics, requires a better attention to the cement type employed.

A primary motivation for conducting this study originates in the lack of available resources on the effect of Portland-limestone cement on the mechanical and hygroscopic properties of compacted earth. As a starting point, the choice is made to focus on a well-characterized soil which behaviour can provide useful insight into the properties of the derived stabilized materials. The effectiveness of stabilization will be assessed firstly based on unconfined compressive strength after different curing ages in normal conditions of temperature and relative humidity. Then, in the interest of exploring the impact of such blended cement on the hygric properties of the selected earth, experimental procedures will be applied for determining the water vapour permeability and the moisture buffering. The global interpretation of findings may contribute to the understanding of cement stabilized compacted earth. 


\section{MATERIALS AND METHODS}

\section{Materials}

Soil: The soil used in this study is one of the reference earths of the RILEM Technical Committee 274-TCE. It comes from a centenarian construction located at the city of Dagneux in "Auvergne Rhône-Alpes" region in south-eastern France. The soil was sieved at $5 \mathrm{~mm}$ then its particle size distribution was determined following the French Standard NF P 94-056. The selected soil is quite fine, with high silt contents (65\%) and quite low sand and gravel contents $(15 \%)$. It encloses also a moderate amount of clay $(20 \%)$ which is generally a desirable condition to build with stabilized earth (Smith and Smith, 1998). The methylene blue tests were carried out on the $80 \mu \mathrm{m}$ fraction of the soil following the French Standard NF P 94-068 to obtain the methylene blue value which had been found to be equal to 1,8 . This latter indicate that the clay of our soil is not much active. The XRD analysis of the raw earth reveals the presence of quartz, albite, illite and traces of vermiculites. This analysis indicates the absence of expensive clays that can have impacts on swelling and cracking of the materials according to the US. Geological Survey (Survey, 2001; El Nabouch, 2016), which is quite consistent with blue value.

Cement: In this work, Portland-limestone cement CEM II/B-LL 32,5R was selected for stabilization. It's a combination of $77 \%$ by mass of clinker, $22 \%$ of limestone and $1 \%$ of minor additional constituents as provided by the manufacturer.

Earth Formulations: For any meaningful stabilization, it's recommended to use at least 4 to $5 \%$ of cement per dry mass of soil to obtain satisfactory mechanical performance of compacted earth (Fitzmaurice, 1958; Rigassi, 1995). Whereas, stabilizing earth with a cement dosage higher than $10 \%$ becomes generally unbeneficial in our region. Thus, the choice made in this study was to stabilize the soil at 5 and $10 \%$ cement by its dry mass. The mechanical and hygric properties of three formulations were evaluated in this work. The unstabilized earth is referenced in what follow by "US" and the stabilized formulations at 5 and $10 \%$ cement are referenced by "SB5" and "SB10" respectively.

\section{Methods}

Sample's Manufacturing and Conditioning: At a first step, the optimum water content and its corresponding dry density were determined by compacting earth's mixtures at different water quantities (from $11 \%$ to $18 \%$ ) with a random increasing step. For each water content, three samples were produced by double compaction with equivalent pressure of $4 \mathrm{MPa}$, using a hydraulic press, inside a cylindrical mold of $35 \mathrm{~mm}$ in diameter. The detailed compaction procedure can be found in (Champire, 2017). As a result, the optimum water content was plotted against the dry density in order to deduce manufacturing properties as summarized in

Table 1. 
Table 1. Formulation's properties

\begin{tabular}{lccc}
\hline Formulations & $\begin{array}{c}\text { Optimum water } \\
\text { content }[\%]\end{array}$ & $\begin{array}{c}\text { Optimum dry density } \\
{\left[\mathrm{g} / \mathrm{cm}^{3}\right]}\end{array}$ & $\begin{array}{c}\text { Average skeletal } \\
\text { density }\left[\mathrm{g} / \mathrm{cm}^{3}\right]\end{array}$ \\
\hline US & $14 \pm 0,09$ & $1,85 \pm 0,005$ & $2,91 \pm 0,02$ \\
SB5 & $14,5 \pm 0,2$ & $1,78 \pm 0,005$ & $2,77 \pm 0,05$ \\
SB10 & $15 \pm 0,3$ & $1,77 \pm 0,005$ & $2,75 \pm 0,05$ \\
\hline
\end{tabular}

Thereafter, samples designed to evaluate the mechanical and hygroscopic performances were prepared at their optimum moisture content and dry density with the same compaction pressure of 4MPa. After demoulding, samples were conditioned in hermetic boxes themselves stored in a climatic chamber at a constant temperature of $23^{\circ} \mathrm{C} \pm 2^{\circ} \mathrm{C}$. The relative humidity inside boxes was maintained using saline solution of $\mathrm{KCO}_{3}$ according to the NF EN ISO 12571 standard. It was checked with a portable sensor (Rotronic HygroLog HL-NT) and it was found to be $49 \%$, consistent with an error lower than $5 \% \mathrm{RH}$. 
Compressive Strength: Simple compression tests were conducted on cylindrical samples $(\Phi 35 \mathrm{~mm} \times \mathrm{h} 70 \mathrm{~mm})$ after different curing ages $(7,28,90$ and 180 days) by applying a continuous loading at a steady rate of $1.2 \mathrm{~mm} / \mathrm{min}$ up to failure. It's worth noting that insufficient sample slenderness and the occurrence of friction between the sample and the press plates can introduce errors in the measurement of compressive strength (Morel, Pkla and Walker, 2007; Ciancio and Gibbings, 2012). In this study, the slenderness ratio of all tested samples is equal to two, which is considered sufficient to avoid measurement errors.

Water Vapour Permeability (wet cup method): The water vapour permeability was carried out as specified in standard ISO-12572 following the so-called "wet cup" method. It involved generating a vapour pressure gradient by setting the relative humidity at $50 \%$ in a climatic chamber and $85 \%$ in a hermetic cup. The water vapor permeability can be determined from the transmission rate of water vapor through the sample when the steady state is reached. The cup design was done according to the procedure described in (McGregor et al., 2014). Therefore, a thin bed of silicon was applied to seal the samples to the plastic cup. A vapour-tight aluminium tape was used to seal the sides of the sample with the side of the cup. The environmental conditions $\left(50 \% \mathrm{RH}\right.$ and $\left.23^{\circ} \mathrm{C}\right)$ were constantly controlled by the climatic chamber. Measurements of mass were done periodically outside of the chamber until a linear function between mass variation and time was established.

Dynamic Moisture Exchange Behavior (Moisture Buffering Value): Moisture buffering tests have been performed following the Nordtest protocol since it is the method commonly used for earth building materials (McGregor et al., 2016). This protocol proposes a unique value, the MBV, defined as "the amount of water that is transported in or out of a material per open surface area, during a certain period of time, when it is subjected to variations in relative humidity of the surrounding air" (Rode et al., 2005). The procedure consists of a repeatedly exposing of the samples to $8 \mathrm{~h}$ in a high-humidity environment $(75 \% \mathrm{RH})$ followed by $16 \mathrm{~h}$ in a low humidity environment $(33 \% \mathrm{RH})$ under constant temperature $\left(23^{\circ} \mathrm{C}\right)$ conditions. To undertake this test, the cylindrical samples having $100 \mathrm{~mm}$ in diameter and $40 \mathrm{~mm}$ thickness, were sealed from water exchange with aluminum tape in all surfaces except one providing one-dimensional conditions. The environmental conditions (temperature and RH cycles) were controlled by a climatic chamber. Samples were weighted periodically until detecting stable cycles, whose are considered reached when the variation between the final mass (end of cycle) of the sample and its initial mass (beginning of cycle) is lower than $0.1 \%$.

\section{RESULTS AND DISCUSSION}

\section{Unconfined Compressive Strength}

Compressive strength of each sample was determined from its failure load and averaged cross section area. Results are plotted in Figure 1 in function of curing age. 
As expected, stabilization has improved the mechanical performance of samples in a global manner with respect to cement dosage. Unstabilized samples showed a relatively stable compressive strength with curing age. Results also indicates that stabilization at 5\% cement didn't improve the performance of compacted earth sample at the early age of 7 days. It appears that moisture content of samples was not sufficient for the complete hydration of this low cement percentage, inducing unreacted particles in sample's matrix.

For both cement dosages, compressive strength shows a rapid increase from 7 to 28 days, followed by an unexpected decrease at the later ages. This may refer to the high rate of moisture content loss at early age, which may cause shrinkage of compressed stabilized earth samples, resulting in the loss of long-term strength. Similar phenomenon had been observed by L. S. Ho et al. (Ho et al., 2018) in the case of sandclay mixture treated with OPC analyzed under drying conditions at $20^{\circ} \mathrm{C} / 60 \% \mathrm{RH}$.

Besides, humid curing is usually recommended for strength development of stabilized compacted earth (Rigassi, 1995) which hadn't been performed in this work. Along the same line, it's a common belief among practitioners that conditioning cement stabilized compacted earth blocks under plastic bags for a duration varying between one and four weeks improve the mechanical performance of their product. However, it's quite hard to find a study in the literature that treat explicitly the effectiveness of humid curing on the short and long-term strength of stabilized compacted earth. It's noteworthy that humid curing effect will lead to case-by-case studies, since long-term strength development will depend strongly on the mineralogical composition of the studied soil. Studying curing effect on the strength development of stabilized compressed earth is outside the bounds of the present work, but it may be investigated in the future.

After being tested in simple compression, samples were oven-dried at $105^{\circ} \mathrm{C}$ and then their skeletal density was measured via a gas pycnometer. Concerning drying procedure, studies demonstrated that oven drying at $105^{\circ} \mathrm{C}$ generate significant damage of the microstructure of cement based materials in the range of capillary porosity (Gallé, 2001; Garci Juenger and Jennings, 2001; Collier et al., 2008). However, analyzing the microstructure of the studied formulations is beyond the scope of this work. Thus, oven drying was applied on all samples as being the simplest drying procedure. Therefore, the mass of a sample is considered as "dry mass" when the difference between two successive masse's readings of the oven-dried sample is negligible with an accuracy of $0.01 \mathrm{~g}$. Results presented in

Table 1 indicate a slight decrease in the skeletal density after stabilization due to the supplementary fine material (cement). 


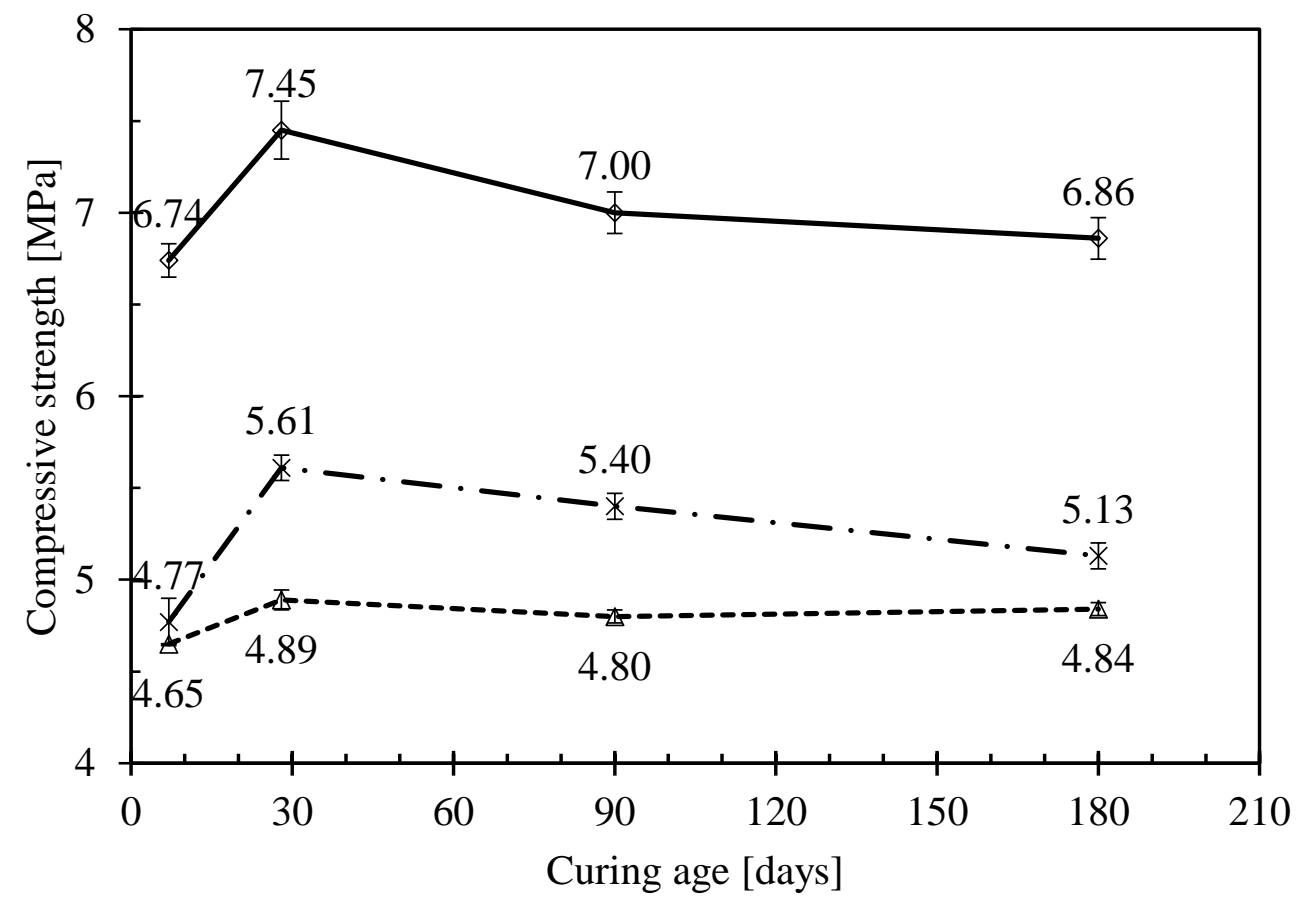

$--\leftrightarrow-\cdot$ US $\longrightarrow \times \cdot-$ SB5 $\longrightarrow$ SB10

Figure 1. Compressive strength variation with curing age and cement content

\section{Water Vapour Permeability}

The water vapour permeability can be deduced from Fick's law of diffusion. The obtained value must be corrected as recommended by EN ISO-12572 standard. This latter correction takes into consideration the resistance of the air layer between the sample and the salt solution. Additional correction, were proposed by (McGregor et $a l ., 2017)$ to take into account the effect of sample thickness. However, it was found here that this correction was of subordinate importance. This may be attributed to the perfect smooth surface state of the prepared samples and the mineralogical composition of the soil used.

The $\mu$ factor is defined as the ratio between the vapour diffusivity coefficients in air and into the porous material. In our case, the effect of stabilization was confirmed by the net increase in $\mu$ factor, up to $37 \%$, in the case of the two cement dosages. To inspect more in depth the effect that may have the age of curing on the calculated $\mu$ factor, water vapor permeability was conducted also at 28 days on only $4 \mathrm{~cm}$ thick samples since thickness effect was neglected. An increase in the calculated $\mu$ factor between 28 and 90 days was signed (Figure 2). Concerning untreated earth, the 28 days value remain in the error bar of the calculated values at 90 days and the slight 
difference between the two values may refer to some existent heterogeneity of the samples. Regarding stabilized formulations, the gap between the calculated $\mu$ factors is much more important. It appears that the $\mu$ factor of stabilized compacted earth may be underestimated if the permeability test is undertaken only after no significant change in the mass of the sample is detected. For stabilized compacted earth, a constant mass is usually attained between 2 and 4 weeks in normal conditions of temperature and relative humidity.

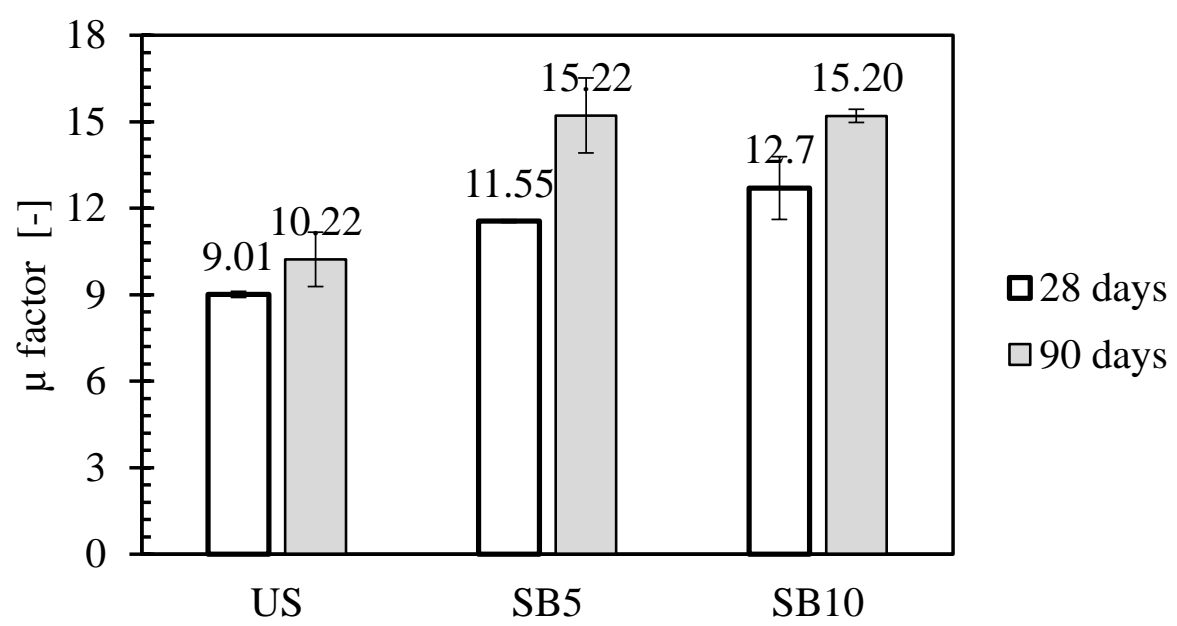

Figure 2. $\mu$ factor calculated for the samples of $4 \mathrm{~cm}$ thickness tested after 28 and 90 days of conditioning

In addition, evaluating the vapour resistance factor only at 28 days, may deliver inaccurate global interpretation of the impact of cement stabilization on this hygric property of earth. At 28 days, $\mu$ factor tend to increase with increasing cement dosage, which is commonly observed in the available literature. However, at 90 days, and even if the delivered value is higher than that obtained at 28 days, increasing cement percentage lead to stagnation of $\mu$ factor. These findings put into question the testing age of the sample. It will be interesting to examine in a future work the microstructural phenomena responsible for behavioural changes with curing age.

\section{Moisture Buffering Value}

The moisture buffering, called $\mathrm{MBV}_{\text {practical, }}$, were calculated from the moisture uptakes and moisture releases of the last stable cycle using the following equation given by Rode et al. (2005):

$$
\mathrm{MBV}_{\text {practical }}=\frac{\Delta \mathrm{m}}{\mathrm{A} \cdot \Delta \mathrm{RH}}
$$


Where $\Delta \mathrm{m}$ is the mass variation (in $\mathrm{g}$ ), $\mathrm{A}$ is the exposed surface and $\Delta \mathrm{RH}$ is the difference between high and low relative humidity levels (in \%).

Results presented in Figure 3 show a reduction in the MBV which is in accordance with previous studies when a decrease in the measured MBV by more than $20 \%$ had been detected at $8 \%$ of cement addition (McGregor et al., 2014). Despite the reduction in the MBV, stabilized product are still lying in the range of good buffering materials according to the classification proposed in (Rode et al., 2005).

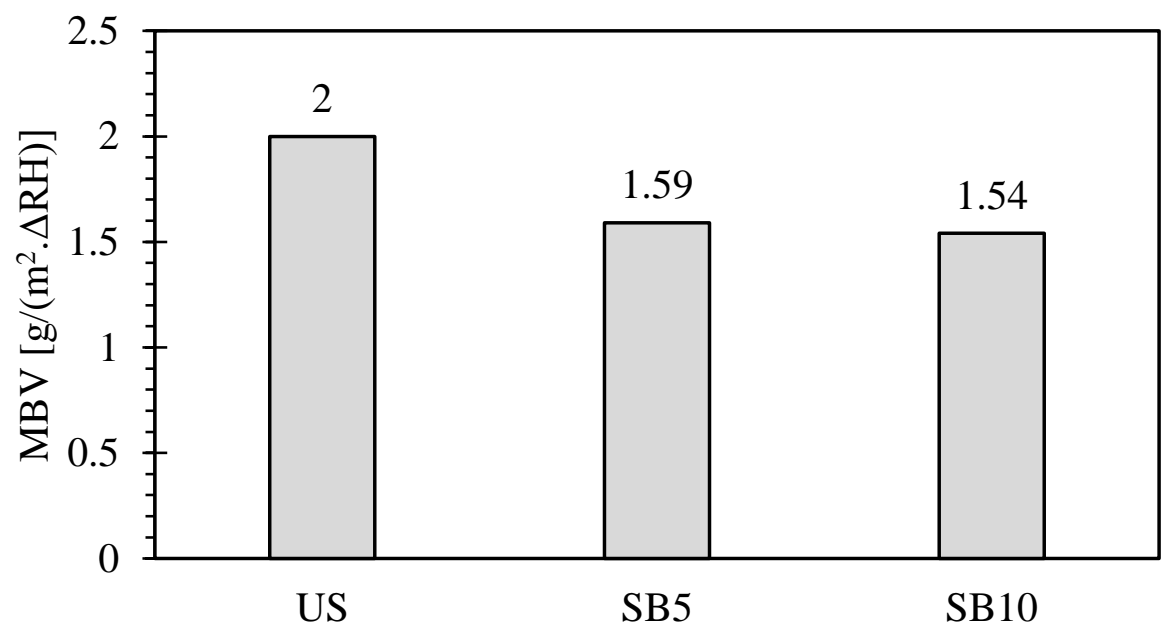

Figure 3 . The calculated moisture buffering value at 28 days

Otherwise, it's clear that an increase in the cement amount from 5 to $10 \%$ didn't affect significantly the quantity of water transported from and to the samples during the test performed. This outcome agrees with the water vapor resistance factor achieved at 90 days, which demonstrated a similar behavior between the two cement dosages. It seems that these hygroscopic properties converge with increasing cement amount from 5 to $10 \%$. It's important to underline that stagnation of the hygroscopic properties obtained in this work cannot be generalized, since they depend mainly on the clay mineralogy of the studied soil and the cement properties together with the applied initial conditioning.

\section{CONCLUSION}

The present work explores the effect of a blended limestone cement type on the unconfined compressive strength, the water vapor resistance factor and the moisture buffering of compacted earth samples in normal conditions. Results are consistent with previous observations on stabilized earth, where stabilization improves mechanical properties and reduces hygroscopic performances. 
The main outcomes can be summarized as follows:

- Unstabilized compacted earth show a relatively stable mechanical and hygric behavior with respect to the age of the tested sample.

- The increase of strength is less marked for stabilized samples at 5\% cement than for the $10 \%$ ones. The highest compressive strength in both cases was reached at 28 days, and was followed by a slight decreasing at 90 and 180 days. This was attributed to the high initial rate of water loss during conditioning.

- The curing age has boosted the vapor resistance factor of stabilized formulations, which show an increase with increasing cement amount at 28 days. However, calculated values at 90 days demonstrate a sort of stagnation with respect to cement dosage.

- Stabilization reduces moisture-buffering capacity computed at the age of 28 days by similar amount without a clear dependency on the dosage of stabilizer in the range of 5 to $10 \%$.

Finally, the findings of this study will lead to further investigations dedicated to analyzing the microstructure of stabilized compacted earth in order to better understand the relation linking the age of the product and its nature (clay nature, porosity, cement type) to its hygroscopic properties. In addition, it would be interesting to check how the long-term compressive strength of cement-stabilized earth evolve depending on the initial conditioning with respect of soil's mineralogy and cement composition.

\section{ACKNOWLEDGEMENTS}

The authors acknowledge Stephane Cointet for his technical support. The financial contributions of the French Technical Association of the Hydraulic Binders Industry (ATILH) and the ANRT (CIFRE project number 2017/1512) are gratefully acknowledged.

\section{REFERENCES}

Allinson, D. and Hall, M. (2012) 'Humidity buffering using stabilised rammed earth materials', Proceedings of the Institution of Civil Engineers - Construction Materials, 165(6), pp. 335-344. doi: 10.1680/coma.11.00023.

Arrigoni, A. et al. (2017) 'Reduction of rammed earth's hygroscopic performance under stabilisation: an experimental investigation', Building and Environment. Pergamon, 115, pp. 358-367. doi: 10.1016/J.BUILDENV.2017.01.034.

Bui, Q. B. et al. (2009) 'Durability of rammed earth walls exposed for 20 years to natural weathering', Building and Environment. Pergamon, 44(5), pp. 912-919. doi: 10.1016/J.BUILDENV.2008.07.001. 
Champire, F. (2017) Étude expérimentale du comportement hydro-mécanique de la terre crue compactée pour la construction. Ecole Nationale des Travaux Publics de l'Etat.

Ciancio, D. and Gibbings, J. (2012) 'Experimental investigation on the compressive strength of cored and molded cement-stabilized rammed earth samples', Construction and Building Materials. Elsevier, 28(1), pp. 294-304. doi: 10.1016/J.CONBUILDMAT.2011.08.070.

Cid-Falceto, J., Mazarrón, F. R. and Cañas, I. (2012) 'Assessment of compressed earth blocks made in Spain: International durability tests', Construction and Building Materials. Elsevier Ltd, 37, pp. 738-745. doi: 10.1016/j.conbuildmat.2012.08.019.

Collier, N. C. et al. (2008) 'The influence of water removal techniques on the composition and microstructure of hardened cement pastes', Cement and Concrete Research. Pergamon, 38(6), pp. 737-744. doi: 10.1016/J.CEMCONRES.2008.02.012.

Fitzmaurice, R. (1958) 'Manual on stabilized soil construction for housing. Technical Assistance Programme. United Nations. New York, USA.'

Gallé, C. (2001) 'Effect of drying on cement-based materials pore structure as identified by mercury intrusion porosimetry: A comparative study between oven-, vacuum-, and freeze-drying', Cement and Concrete Research. Pergamon, 31(10), pp. 1467-1477. doi: 10.1016/S0008-8846(01)00594-4.

Garci Juenger, M. C. and Jennings, H. M. (2001) 'The use of nitrogen adsorption to assess the microstructure of cement paste', Cement and Concrete Research. Pergamon, 31(6), pp. 883-892. doi: 10.1016/S0008-8846(01)00493-8.

Heathcote, K. (2011) 'The thermal performance of earth buildings', Informes de la Construcción, 63(523), pp. 117-126. doi: 10.3989/ic.10.024.

Ho, L. S. et al. (2018) 'Analysis of strength development in cement-treated soils under different curing conditions through microstructural and chemical investigations', Construction and Building Materials. Elsevier Ltd, 166, pp. 634-646. doi: 10.1016/j.conbuildmat.2018.01.112.

McGregor, F. et al. (2012) 'The effect of stabilisation on humidity buffering of earth walls', 6th International Conference on Building with Earth, LEHM 2012, (October), pp. 73-79. doi: ISBN 9783000396496.

McGregor, F. et al. (2014) 'Conditions affecting the moisture buffering measurement performed on compressed earth blocks', Building and Environment. Pergamon, 75, pp. 11-18. doi: 10.1016/J.BUILDENV.2014.01.009. 
McGregor, F. et al. (2016) 'A review on the buffering capacity of earth building materials A review on the buffering capacity of earth building materials', (January). doi: 10.1680/jcoma.15.00035.

McGregor, F. et al. (2017) 'Procedure to determine the impact of the surface film resistance on the hygric properties of composite clay/fibre plasters', Materials and Structures, 50(4), p. 193. doi: 10.1617/s11527-017-1061-3.

Morel, J.-C., Pkla, A. and Walker, P. (2007) 'Compressive strength testing of compressed earth blocks'. Elsevier, 21(2), pp. 303-309. doi: 10.1016/J.CONBUILDMAT.2005.08.021.

Morel, J. et al. (2001) 'Building houses with local materials: means to drastically reduce the environmental impact of construction', 36, pp. 1-7.

Morel, J., Bui, Q. B. and Hamard, E. (2012) 'Weathering and durability of earthen material and structures. In Modern earth buildings. Woodhead publishing, M.R. Hall, R. Lindsay and M. Krayenhoff eds.'

Morel, J. C. et al. (2013) 'Some observations about the paper "earth construction: Lessons from the past for future eco-efficient construction" by F. Pacheco-Torgal and S. Jalali', Construction and Building Materials, 44(November 2017), pp. 419-421. doi: 10.1016/j.conbuildmat.2013.02.054.

El Nabouch, R. (2016) Mechanical behavior of rammed earth walls under Pushover tests - PhD Thesis.

Pacheco-Torgal, F. and Jalali, S. (2012) 'Earth construction: Lessons from the past for future eco-efficient construction', Construction and Building Materials. Elsevier, 29, pp. 512-519. doi: 10.1016/J.CONBUILDMAT.2011.10.054.

Rigassi, V. (1995) Compressed earth blocks: Manual of production.

Rode, C. et al. (2005) 'Nordtest project on moisture buffer value of materials'.

Smith, G. N. and Smith, I. N. (1998) 'Elements of Soil Mechanics.', 7th Edn. Blackwell Science Limited. Cambridge, England.

Soudani, L. et al. (2016) 'Assessment of the validity of some common assumptions in hygrothermal modeling of earth based materials', Energy and Buildings. Elsevier, 116, pp. 498-511. doi: 10.1016/J.ENBUILD.2016.01.025.

Survey, U. S. G. (2001) A Laboratory Manual for X-Ray Powder Diffraction, OpenFile Report 01-041. 
Venkatarama Reddy, B. V. (2012) 'Stabilised soil blocks for structural masonry in earth construction', Modern Earth Buildings. Woodhead Publishing, pp. 324-363. doi: 10.1533/9780857096166.3.324.

Walker, P. J. (1995) 'Strength, durability and shrinkage characteristics of cement stabilised soil blocks', Cement and Concrete Composites. Elsevier, 17(4), pp. 301310. doi: 10.1016/0958-9465(95)00019-9. 